\title{
EL PROYECTO EDITORIAL COMO PARTE DEL PROYECTOÉTICO-POLÍTICO PROFESIONAL
}

\section{[EN] THE PUBLISHING PROJECT AS PART OF THE PROFESSIONAL ETHICAL-POLITICAL PROJECT}

El Colegio de Profesionales del Trabajo Social de Puerto Rico lleva más de una década en el proceso de desarrollo de un proyecto ético-político profesional que le dé orientación a la praxis de quienes conformamos esta clase profesional. Entre los principales propósitos que tiene este proyecto se encuentra estructurar las dimensiones teórico-metodológicas, técnico-operativas, y éticopolíticas de la profesión de Trabajo Social en Puerto Rico (Barreto Cortez, 2010). Sin embargo, el estructurar estas dimensiones desde la institucionalidad del Colegio, más que un fin en sí mismo, tiene como meta el poder determinar cómo, desde el Trabajo Social, podemos aportar a la concretización del proyecto societario al cual aspiramos. Lo cual a su vez, nos ha obligado a pensarnos a nosotros y nosotras mismas como clase profesional para determinar: ¿cuál ha sido el rol histórico del Trabajo Social puertorriqueño en función del sistema económico-político imperante (neoliberalismocolonial)?, ¿éticamente, se sostiene el que mediante nuestro accionar profesional aportemos a la reproducción de un sistema económico-político que crea y perpetúa las condiciones de opresión que enfrentan los sectores poblaciones con los cuales trabajamos?, de no aceptar el orden neoliberal-colonial vigente, ¿a qué otro proyecto societario debemos aspirar como clase profesional que sea acorde con los valores y ética que nos guían? 
Ha sido en el contexto de las reflexiones arriba planteadas que, desde el año 2012, nuestro gremio profesional asumió como una de sus responsabilidades la publicación de una revista profesional, tanto de impacto nacional como internacional, que permitiera la presentación de nuevo conocimiento científico dirigido a abordar y problematizar nuestro accionar profesional desde referentes teóricos críticos. Este aporte se amplía hoy mediante la publicación del volumen número ocho de la revista Voces desde el Trabajo Social. El que hoy se pueda presentar este volumen, es gracias a la labor colectiva de múltiples profesionales que, durante ya casi una década, han donado de su tiempo en pro del fomento de la creación y difusión del conocimiento científico desde el Trabajo Social dirigido a la búsqueda de una sociedad caracterizada por la justicia y la equidad.

Partiendo de lo anterior, en el presente volumen encontrarán artículos profesionales, tanto de investigación como de revisión, cuyos aportes van dirigidos a reflexionar respecto al rol del Trabajo Social en la habilitación de los derechos humanos vinculados con: la educación (González-Parés, 2020; Jusino-Sierra, 2020; Martínez Medina, Silva Martínez, Oliveras Del Río \& Álvarez Soto, 2020; Soto-Román, 2020; Vázquez-Díaz, Ceh-Alvarado \& Carrillo-Puc, 2020), el trabajo (Carabajal, 2020; Gayol Santana, 2020), la salud (Contreras \& Rivera Díaz, 2020; Rivera-Díaz, 2020; Rosa-Dávila \& Mercado-Sierra, 2020) la espiritualidad (Morales Alejandro, 2020), la paz (Correa-Delgado \& Sandoval Bueno, 2020), y el medio ambiente (Álvarez-Rosario \& Crespo Rivera, 2020). También, identificarán un análisis crítico de la autoría de Mallardi (2020), respecto a los fundamentos humano-genéricos, las expresiones histórico-sociales y las determinaciones objetivas y subjetivas de la vida cotidiana, 
reflexión indispensable para poder dar cuenta de la complejidad en la cual se ve inmersa el ejercicio profesional desde el Trabajo Social.

Habiendo reconocido los significativos aportes que durante la pasada década ha alcanzado nuestro gremio profesional en la generación y transmisión del conocimiento científico desde una perspectiva crítica, es meritorio plantearse: ¿qué aun nos falta por hacer desde el campo de la edición para lograr el fortalecimiento y difusión de nuestro proyecto profesional? Ante dicha pregunta, planteo la necesidad de que, al igual que se ha realizado con la revista Voces desde el Trabajo Social, se asuma la necesidad de organizar una colección editorial dirigida a documentar, proponer y difundir, tomando como base lo ya adelantado mediante las reflexiones generadas durante la pasada década, el Trabajo Social que aspiramos se ejerza en Puerto Rico. Esto, enfatizando en las dimensiones éticas, epistémicas, teóricas, metodológicas y técnicas de nuestra profesión. El contexto social actual, caracterizado por el avance del neoliberalismo y la vulneración sistemática de los derechos humanos, hace necesaria la revisión y actualización de los referentes editoriales utilizados en los espacios académicos y agenciales del país como fundamento de la acción profesional. Frente a lo anterior, el establecimiento de una nueva colección editorial, basada en el proyecto ético-político, debería servir como herramienta fundamental para la revisión de nuestro quehacer profesional y el fomento de un Trabajo Social teórica y metodológicamente crítico.

Iván de Jesús Rosa ${ }^{1}$

Editor General 


\section{Referencias}

Álvarez-Rosario, G., \& Crespo Rivera, E. (2020). El diseño de un curso subgraduado de asuntos ambientales para el Trabajo Social puertorriqueño. Voces desde el Trabajo Social, 8(1), 310-329. https://doi.org/10.31919/voces.v8i1.229

Barreto Cortez, E. (2010). Reflexiones acerca de la construcción de un proyecto ético-político profesional. Análisis, XI(1), 49-67.

Carabajal, J. D. (2020). ¿Trabajar o no trabajar? Esa es la cuestión. Un cuestionamiento sobre las dificultades en la inserción laboral de algunas personas con discapacidad en Santiago del Estero, Argentina. Voces desde el Trabajo Social, 8(1), 66-87. https://doi.org/10.31919/voces.v8i1.230

Contreras, V., \& Rivera Díaz, M. (2020). Las contradicciones del capitalismo: breves apuntes sobre la salud en Puerto Rico desde los planteamientos de David Harvey. Voces desde el Trabajo Social, 8(1), 250-269. https://doi.org/10.31919/voces.v8i1.226

Correa-Delgado, J. S., \& Sandoval Bueno, C. D. (2020). Trabajo Social y construcción de paz: una reflexión desde la práctica interdisciplinaria en el marco de la implementación del acuerdo de paz entre las FARC y el Estado colombiano. Voces desde el Trabajo Social, 8(1), 290-309. https://doi.org/10.31919/voces.v8i1.228

Gayol Santana, L. (2020). ¿Trabajo digno en la zona central de Puerto Rico?: Abordaje del Trabajo Social a la política pública sobre la escasez de trabajadores agrícolas. Voces desde el Trabajo Social, 8(1), 108-129. https://doi.org/10.31919/voces.v8i1.220 
González-Parés, F. J. (2020). La exclusión educativa en Puerto Rico: Un abordaje histórico-crítico y decolonial del fenómeno educativo en el sistema de educación pública de Puerto Rico. Voces desde el Trabajo Social, 8(1), 130-149. https://doi.org/10.31919/voces.v8i1.221

Jusino-Sierra, F. (2020). Educación sexual ¿tarea para los padres?: Abordaje desde una perspectiva crítica a la política educativa contemporánea de Puerto Rico. Voces desde el Trabajo Social, 8(1), 200-255. https://doi.org/10.31919/voces.v8i1.224

Mallardi, M. W. (2020). Sobre la vida cotidiana.

Aproximaciones a sus fundamentos y expresiones

histórico-sociales. Voces desde el Trabajo Social, 8(1), 226-249. https://doi.org/10.31919/voces.v8i1.225

Martínez Medina, J. J., Silva Martínez, E., Oliveras Del Río, J., \& Álvarez Soto, S. (2020). Educación con perspectiva de género desde el diálogo entre las experiencias y saberes infantiles. Voces desde el Trabajo Social, 8(1), 88-107. https://doi.org/10.31919/voces.v8i1.219

Morales Alejandro, L. I. (2020). La espiritualidad en la niñez. Voces desde el Trabajo Social, 8(1), 40-65. https://doi.org/10.31919/voces.v8i1.218

Rivera-Díaz, M. (2020). A despatologizar y humanizar la salud mental desde las instituciones académicas: propuestas para un accionar ético político. Voces desde el Trabajo Social, 8(1), 150-175. https://doi.org/10.31919/voces.v8i1.222 
Rosa-Dávila, E., \& Mercado-Sierra, M. A. (2020). Salud Mental Comunitaria: Una Explicación del Modelo. Voces desde el Trabajo Social, 8(1), 270-289. https://doi.org/10.31919/voces.v8i1.227 Soto-Román, J. (2020). La formación profesional del Trabajo Social en Puerto Rico ante el contexto actual: Desafíos y posibilidades. Voces desde el Trabajo Social, 8(1), 176-199.

https://doi.org/10.31919/voces.v8i1.223

Vázquez-Díaz, G., Ceh-Alvarado, A., \& Carrillo-Puc, R. (2020). Sistematización de la intervención profesional durante el contexto de la COVID-19, para la valoración de la situación socioeconómica de jóvenes aspirantes a una institución educativa del sureste de México. Voces desde el Trabajo Social, 8(1), 16-39. https://doi.org/10.31919/voces.v8i1.217

${ }^{1}$ Iván de Jesús Rosa

Editor General del Colegio de Profesionales del Trabajo Social de Puerto Rico Catedrático Auxiliar, Universidad Ana G. Méndez, Carolina, Puerto Rico.

\dei1@uagm.edu

(iD ORCID ID https://orcid.org/0000-0002-0255-8337 